\title{
Incorporation of Natural Fibres in Rendering Mortars for the Durability of Walls
}

\author{
Cinthia Maia Pederneiras ${ }^{1,2, *(1)}$, Rosário Veiga ${ }^{2}\left(\mathbb{C}\right.$ and Jorge de Brito ${ }^{1}$ (1) \\ 1 CERIS, Instituto Superior Técnico, University of Lisbon, Av. Rovisco Pais, 1, 1049-001 Lisbon, Portugal; \\ jb@civil.ist.utl.pt \\ 2 National Laboratory for Civil Engineering, Av. do Brasil 101, 1700-066 Lisbon, Portugal; rveiga@lnec.pt \\ * Correspondence: cinthiamaia@tecnico.ulisboa.pt
}

Citation: Maia Pederneiras, C.; Veiga, R.; de Brito, J. Incorporation of Natural Fibres in Rendering Mortars for the Durability of Walls. Infrastructures 2021, 6, 82. https://doi.org/10.3390/ infrastructures6060082

Academic Editor: Md. Safiuddin

Received: 12 May 2021

Accepted: 29 May 2021

Published: 1 June 2021

Publisher's Note: MDPI stays neutral with regard to jurisdictional claims in published maps and institutional affiliations.

Copyright: (C) 2021 by the authors. Licensee MDPI, Basel, Switzerland. This article is an open access article distributed under the terms and conditions of the Creative Commons Attribution (CC BY) license (https:// creativecommons.org/licenses/by/ $4.0 /)$.
Abstract: One of the main functions of renders, together with the overall aesthetic appearance of the building, is the protection of the walls against external aggressive actions, such as water, salts solutions, erosion, and mechanical impacts. However, some anomalies of renders may drastically hinder their protection ability. In fact, cracking, high water permeability, and loss of adherence to the substrate of renders limit their barrier effect and favour the exposure of the substrate to external actions. The incorporation of fibres in mortars is commonly pointed out to reduce their cracking susceptibility, due to the probable enhancement in tensile strength and ductility of the composite. The use of lime in substitution of the part of the cement binder is seen as a method to reduce the modulus of elasticity and therefore enhance the resistance to cracking due to drying shrinkage. Therefore, this study investigates the wall protection-related properties of natural fibre-reinforced renders with cement-lime as a binary binder at 1:1:6 volumetric ratio. With this purpose, wool, coir, and flax fibres are used at $20 \%$ by total mortar volume and the water behaviour, cracking susceptibility, and adherence to the substrate of the mortars are assessed. Specifically, the water absorption by capillarity, drying rates, permeability to water under pressure, adherence strength, and shrinkage are evaluated. In order to evaluate the renders' durability and therefore the durability of the protection to the walls, an artificial accelerated ageing test is performed based on heatingfreezing and humidification-freezing cycles. The results indicate that the fibres' addition reduced the shrinkage and modulus of elasticity of the mortars, which suggests lower susceptibility to cracking. The addition of fibres in mortars seemed to slightly affect their water performance and only at early ages. From the results, it was concluded that the adherence strength is not affected by the fibres' incorporation. The fibres seem also to reduce the impacts of the ageing cycles on the mortar and the improvements provided by the fibres' addition to the mortars' performance remained after ageing when compared to the mortars without fibres, thus being a potential alternative to increase their durability. These aspects are particularly important for buildings, since they can extend their service life and promote their sustainability.

Keywords: durability; natural fibre-reinforced mortar; cement-lime mortars; sustainability; render

\section{Introduction}

The main functions of the render are to guarantee the aesthetic appearance and protection of building walls. The render, as the coating of the wall, should protect it against aggressive actions, and as well provide hygrothermal and acoustic comfort, besides having decorative functions [1]. One of the main causes of degradation of a building is a defect in the waterproofing ability of the render, which strongly influences the walls durability. The presence of water and its transportation inside masonry negatively affect its functionality $[2,3]$. In general, the renders should be mechanically weaker and more permeable to water vapour than the underlying masonry, since coatings must accommodate the mechanical movements of the building and quickly dry the absorbed water to avoid its 
spreading throughout the structure [4]. Therefore, renders should present a low capillary water absorption coefficient, in order to inhibit a fast penetration of water in high quantity. Furthermore, the rendering mortars must be able to easily evaporate the infiltrated water, since a prolonged contact with water is one of the most significant causes of degradation of the walls.

Besides the hygric properties of the mortars, their cracking behaviour may also seriously affect their protection ability, concerning water, and aggressive solutions. It is well known that the mortars tend to be very susceptible to cracking, since the development of stresses due to the mortar's shrinkage and hygrothermal dimensional variations is difficult to control. It is important to enhance the cracking resistance of the render in order to minimize the cracks and prevent the water to infiltrate. Therefore, alternatives to improve the cracking resistance of mortars have been investigated. The use of two binders as lime and cement can reduce the shrinkage and stiffness of the mortars [5]. Another way to improve cracking susceptibility is the use of fibres in the composites, since they improve their toughness, which is a relevant factor for cracking performance [6,7]. The incorporation of fibres in cementitious composites is a potential alternative to enhance their cracking resistance and extend their life cycle, as well as increasing the durability of the walls.

As an innovative solution, natural fibres have been used as addition in reinforced mortars, considering that natural fibres can contribute to improve the mortars' tensile properties while being environmental-friendly, due to low pollutants emissions, large availability, low cost, and low incorporated energy, besides the characteristics of biodegradability $[8,9]$. In this case, the sustainability factor was enhanced as the natural fibres used are wastes from industry.

Beyond the properties that enhance the protection ability of renders, the durability of the mortars themselves is very relevant to ensure the longevity of that protection. In spite of natural fibres' advantages, previous studies highlighted that their efficiency may be compromised in an alkaline environment, such as a cementitious matrix [7,10-12]. The natural fibres may reduce their mechanical strength and toughness when exposed to an alkaline cementitious matrix, due to the fibres' mineralization, which means a migration of hydrated products inside the fibre's structure [11]. Therefore, studies have investigated the long-term durability of natural fibres in cement composites. Toledo Filho et al. [7] investigated the durability of sisal and coconut fibres in cement mortars. The authors reported that the alkaline attack of the fibres depends on many factors, such as the fibre's type, cement matrix composition and porosity, and the ageing environment. Santos et al. [13] studied the durability of eucalyptus and sisal fibres in cement composites and proposed an accelerated carbonation curing as an alternative to improve the long-term durability of vegetable fibre-reinforced composites. Józwiak-Niedzwiedzka and Fantilli [14] reported that the reduction of clinker content in the cementitious matrix can improve the natural fibre-reinforced composite. Ardanuy et al. [15] identified another way to increase the durability of these composites, which is to modify the fibre's structure with chemical or physical treatments. Wei and Meyer [10] increased the durability of the sisal fibre-reinforced cement composites with a partial replacement of cement by rice husk ash, owing to their high pozzolanic activity.

The aim of this work is to evaluate the protection ability properties of rendering mortars with natural fibres and the durability of the renders themselves. Moreover, it intends to evaluate the use of lime as substitution of a part of the cement as a feasible alternative to increase the cracking resistance of the mortars. More protective and durable renders can reduce the deterioration of the walls and increase the building's lifetime. For this purpose, the selected tests were performed in order to investigate the water, cracking, adherence and durability performance of the mortars for rendering purpose. In order to evaluate the wall protection-related properties of the mortar, the tests performed were: water absorption by capillarity, drying curves, open porosity, permeability to water under pressure, modulus of elasticity, dimensional variation, and adherence strength. 
Furthermore, to evaluate the durability performance of the mortars, an artificial accelerated ageing test was carried out, based on heating-freezing and humidification-freezing cycles.

In this paper, the natural fibres used were wool, coir, and flax fibres, $1.5 \mathrm{~cm}$ long, incorporated as a $20 \%$ addition, as in previous researches [16-18], it was observed that those were the most favourable incorporation conditions in cement-lime mortars in order to achieve the best results concerning the target characteristics.

Two reference mortars were produced: cement mortar with a volumetric ratio of 1:4 (cement:aggregates) and cement-lime mortar at 1:1:6 (cement:air-lime:aggregates), with the purpose of analysing the durability in two different matrices. Moreover, the experimental test programme was conducted in order to investigate properties specifically related with the protection ability.

\section{Materials and Methods}

The materials used and the standards used in each of the tests performed are described in this section.

\section{Materials}

To evaluate the durability properties of natural fibre-reinforced mortars, three fibres were tested: wool, coir, and flax. The natural fibres studied in this work were wastes from different industries. Wool fibres were obtained from sheep in Serra da Estrela (Portugal); after shearing, it is processed industrially for textile uses and the rejected pieces do not have a proper disposal. The Portuguese clothing manufacturer (Burel Factory TrendBurel, Lda) provided the wool fibre waste. Coir fibres were waste from a Portuguese insulation company (Amorim Cork Insulation). Flax fibres were waste rejected by the textile industry. The fibres were previously washed with neutral detergent to remove their impurities and manually cutting and are presented in Figure 1. Before their introduction in the mix, the fibres were previously distributed inside a proper closed receptacle with blown compressed air in order to achieve an adequate dispersion and disentangle the fibres.

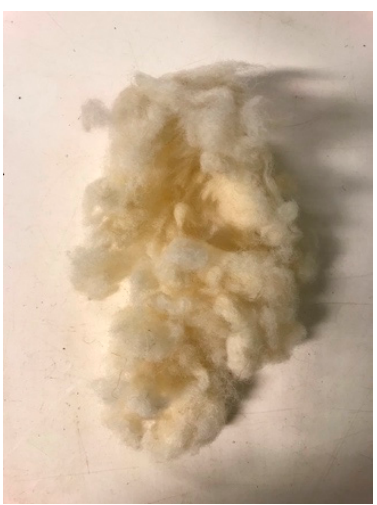

(a)

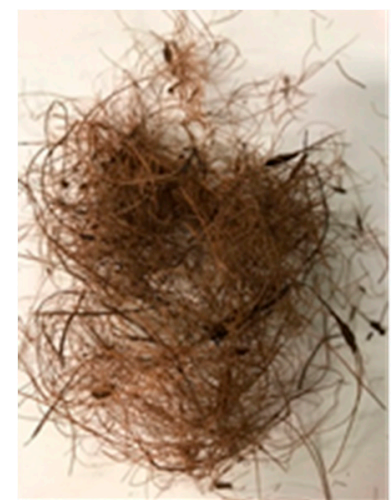

(b)

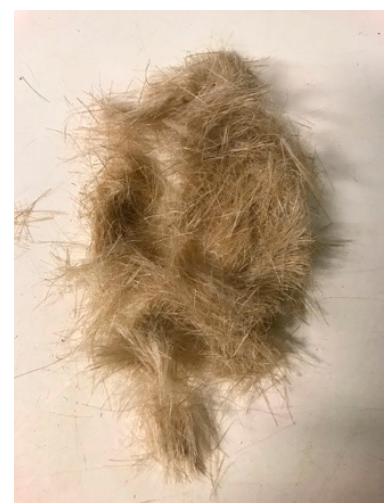

(c)

Figure 1. Natural fibres used: (a) wool fibres, (b) coir fibres and (c) flax fibres.

The mortars were produced as binary binders with cement CEM II/B-L $32.5 \mathrm{~N}$ (according to EN 197-1 [19]), from the Portuguese cement producer Secil, and calcium hydrated powder air-lime CL80-S (according to EN 459-1 [20]), from the Portuguese company Calcidrata S.A. The aggregate used was natural sand from the Tagus River (Portugal), from the Portuguese company Areipor, Areias Portuguesas S.A. The sand was washed and calibrated by the company. The sand was sieved to obtain the size distribution defined, which is presented in a previous publication [16].

The modified mortars were produced at volumetric ratio of 1:1:6 (cement:air-lime: aggregates) and with an incorporation of $20 \%$ (by total mortar volume) $1.5 \mathrm{~cm}$ long natural fibres. The volume fraction and length of the fibres were previously defined as an optimal 
ratio to improve the mortars' ductility, according to previous studies [16-18]. In order to evaluate the composition most commonly used in wall renderings in Portugal, a reference mortar with a volumetric ratio of 1:4 (cement: aggregates) was also produced. Therefore, five mortars were designed and identified as follows:

- REF 1:4-reference cement mortar at 1:4 volumetric ratio ( $0 \%$ incorporation);

- $\quad$ REF 1:1:6 - reference cement-lime mortar at 1:1:6 volumetric ratio ( $0 \%$ incorporation);

- W 1.5-20cl-20\% wool fibre incorporation at 1:1:6 volumetric ratio;

- C 1.5-20cl-20\% coir fibre incorporation at 1:1:6 volumetric ratio;

- F 1.5-20cl-20\% flax fibre incorporation at 1:1:6 volumetric ratio.

\section{Methods}

These mortars were previously characterized in terms of fresh and mechanical behaviour [16-18]. In this work, the tests performed were focused on analysing the wall protection-related properties of the mortars. For this purpose, the standards used are shown in Table 1. Prismatic specimens with dimensions of $160 \times 40 \times 40 \mathrm{~mm}^{3}$ were used for the hardened mortars tests. A layer of $20 \mathrm{~mm}$ of mortar was applied on a brick in order to test the mortars on a porous substrate. The number of prismatic specimens used was three for each test; in the case of adherence strength and permeability to water under pressure, tested on the rendered bricks, 1 and 2 bricks, respectively, were used. Nonetheless, for adherence strength, the brick was tested five times.

Table 1. Methods used for each test.

\begin{tabular}{|c|c|c|c|}
\hline Test & Ages Analysed (Days) & European Standard & Specimens \\
\hline Water absorption by capillarity & 28,365 & EN 1015-18 [21] & Prism \\
\hline Drying & 28,365 & EN 16322 [22] & Prism \\
\hline Open porosity & 28,365 , after ageing & EN 1936 [23] & Half of Prism \\
\hline Artificial ageing & 28 & EN 1015-21 [24] & Brick \\
\hline Aesthetical appearance & 28 , after ageing & - & Brick \\
\hline Adherence strength to the substrate & 28 , after ageing & EN 1015-21 [24] & Brick \\
\hline Permeability to water under pressure & 28 , after ageing & EN 1015-21 [24] & Brick \\
\hline Modulus of elasticity by ultra-sound pulse velocity & 28 , after ageing & EN 12504-4 [25] & Brick \\
\hline Shrinkage & up to 90 & Cahier 2669-4 [26] & Prism \\
\hline
\end{tabular}

The mortar's workability was kept constant in the spread range $140 \pm 5 \mathrm{~mm}$. This value of consistency was chosen after an application on the bricks, since the mortars should be workable to be applied on porous substrates. The hardened mortars were submitted to curing conditions according to EN 1015-11 [27], keeping the specimens in the moulds for $48 \mathrm{~h}$ after production at a temperature of $20 \pm 2{ }^{\circ} \mathrm{C}$ and relative humidity of $95 \pm 5 \%$. After that, the mortars were demoulded and kept in the same conditions for 5 days. After 7 days of production, the specimens were kept at the same temperature, but the relative humidity was reduced to $65 \pm 5{ }^{\circ} \mathrm{C}$, until 28 days. The specimens with a $20 \mathrm{~mm}$ layer of mortar on a brick (Figure 2) were cured in the same conditions. The only exception were the specimens for the dimensional variation test (shrinkage), which were submitted to a relative humidity of $50 \pm 5 \%$ and a temperature of $23 \pm 2{ }^{\circ} \mathrm{C}$ for the 90 days of testing.

The drying test was performed immediately after the water absorption by capillarity test, using the same specimens. The drying test was conducted under conditions of a temperature of $20 \pm 2{ }^{\circ} \mathrm{C}$ and relative humidity of $65 \pm 5 \%$. The specimens were weighted at $30,60,90,270,450$, and $1440 \mathrm{~min}$, and then every $24 \mathrm{~h}$ until they reached a constant mass. The drying rates and the drying index were calculated. From the drying curves of water loss per hour, the first phase drying rate, which represents the kinetic of transportation of liquid water, was defined. The rate of the second and third phases of drying were calculated through the slope of the linear part of the drying curve (unit per area) over the square root of time and mean respectively the transportation of mix liquid and vapour and of water vapour to the surface. The drying index is an indicator of transportation speed 
and quantity of liquid and vapour water inside the mortar, as well as the easiness with which water exits through the mortar pores.
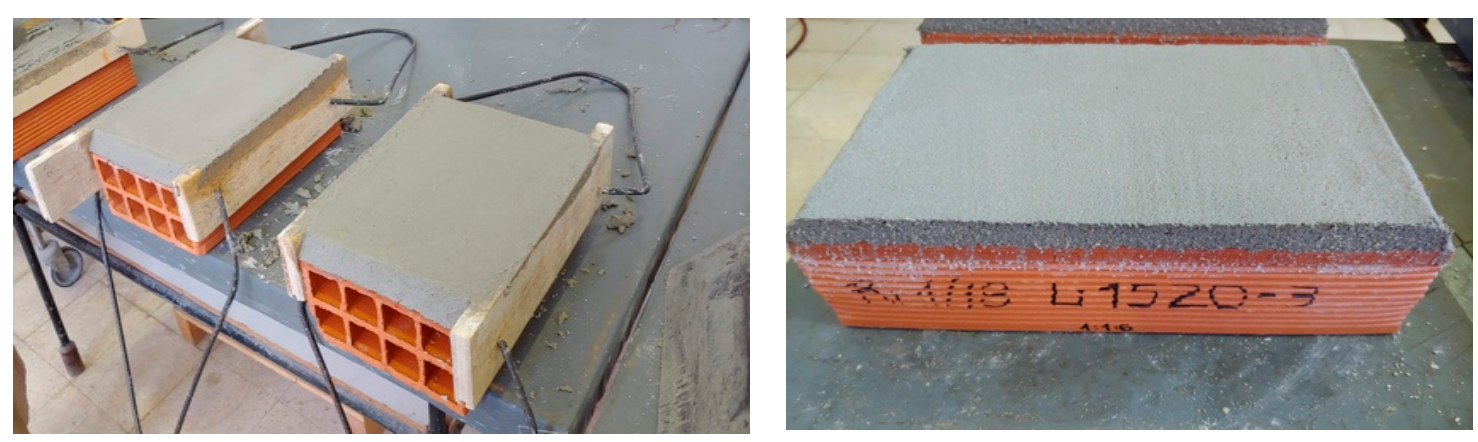

Figure 2. Mortar application on a brick.

From the ultrasound pulse velocity, the dynamic modulus of elasticity was calculated by Equation (1). The $K$ coefficient is calculated from Equation (2), $v$ is the Poisson coefficient (0.2), $V$ is the ultrasound pulse velocity calculated and $\rho$ is the bulk density of the mortar.

$$
\begin{gathered}
M E_{U S}=K \times V^{2} \times \rho \times 10^{-6}, \\
K=\frac{(1+v) x(1-2 v)}{(1-v)} \approx 0.9 .
\end{gathered}
$$

The durability evaluation of the mortars was based on the artificial accelerated ageing test, which consisted of eight heating-freezing cycles followed by eight humidificationfreezing cycles. The former cycle is composed of heating by infrared radiation at $60 \pm 2{ }^{\circ} \mathrm{C}$ for $8 \mathrm{~h} \pm 15 \mathrm{~min}$ and freezing at temperature of $-15 \pm 1{ }^{\circ} \mathrm{C}$ for $15 \mathrm{~h} \pm 15 \mathrm{~min}$. The humidity cycle consisted of $8 \mathrm{~h} \pm 15 \mathrm{~min}$ of water sprinkling at a temperature of $20 \pm 2{ }^{\circ} \mathrm{C}$ and freezing again at $-15 \pm 1{ }^{\circ} \mathrm{C}$ for $15 \mathrm{~h} \pm 15 \mathrm{~min}$. The specimens were at the normalized conditions of $20 \pm 2{ }^{\circ} \mathrm{C}$ and relative humidity of $65 \pm 5 \%$ for $1 \mathrm{~h} \pm 2 \mathrm{~min}$ within the cycles. Between the cycles, the specimens were subjected to a normalized condition for at least $48 \mathrm{~h}$. Figure 3 illustrates the cycles of the artificial ageing.
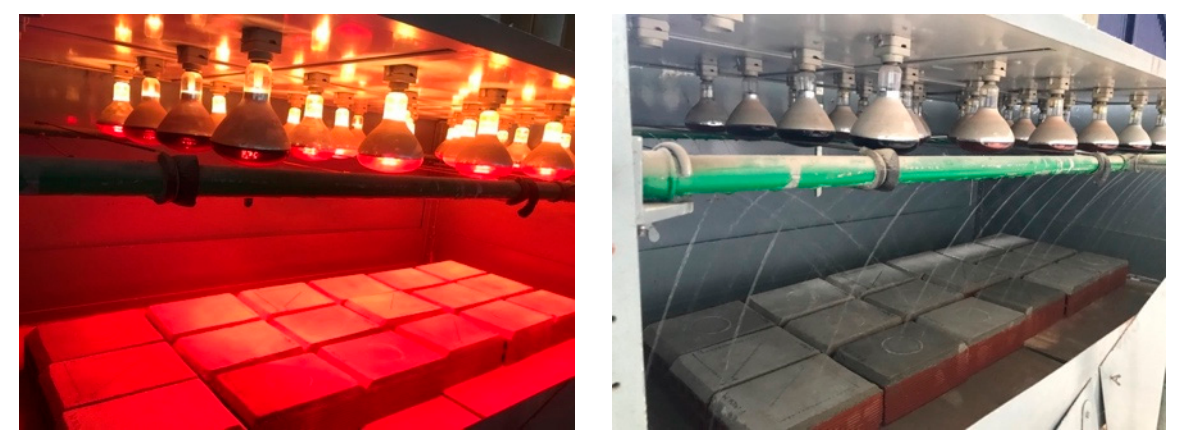

Figure 3. Illustration of the artificial ageing.

The mortars' behaviour was analysed before and after the artificial accelerated ageing, namely the adherence strength to the substrate, ultra-sound pulse velocity test and permeability to water under pressure test. From the ultra-sound pulse velocity test, it was possible to determine the modulus of elasticity of the mortars. The permeability to water under pressure test was performed using a cylinder that maintained a pressure of $260 \mathrm{~mm}$ of water and measuring the water level variations. 


\section{Results and Analysis}

\subsection{Wall Protection-Related Properties}

In order to analyse the rendering mortars' protection capacity of the walls, some properties were evaluated, namely their water performance, cracking resistance, and adhesive strength.

Concerning the water behaviour, renders should prevent a fast and high water absorption and at the same time favour the easy release of the water absorbed by liquid or vapour transportation. The render's performance should involve the protection of the substrate from the water absorption, since the water movement inside the masonry structure is one of the most significant causes of its degradation [2]. To assess the mortars' water behaviour, the water absorption by capillarity, drying process, open porosity and permeability to water under pressure were evaluated.

Other factors that also drastically affect the render's functional capacity are the cracking susceptibility and loss of adherence to the substrate. Therefore, to analyse the cracking performance of the mortars, the modulus of elasticity and dimensional variation (shrinkage) were determined. These tests are strongly related to the mortars' cracking susceptibility. The cracking resistance of renders is mainly due to the mortar's capacity to withstand the tensile stresses induced by restrained shrinkage, due to the fact that the mortars are applied on a relatively rigid substrate [28]. The modulus of elasticity is directly related to the cracking propensity of mortars, since higher deformation capacity give rise to the ability to absorb the internal stresses imposed. Therefore, a lower modulus of elasticity can indicate that the mortar may withstand stresses without cracking. There are several factors that influence the cracking of the render, besides the mortars' characteristics, but, under similar external conditions, a high deformation capacity allows the mortars to better dissipate the stress without cracking.

The adherence strength test was also performed. It is well known that a good adherence to the substrate enables an adequate distribution of stresses and, consequently, increases the renders' protection capacity of the walls.

\subsubsection{Water Absorption}

The water absorption by capillarity test of the mortars was performed at 28 and 365 days. The capillary coefficient was calculated through the water absorbed between 10 and 90 minutes per unit and square root of time, and the results are presented in Figure 4. The results show that for cement-lime mortars, the water absorption by capillarity increases, as expected, since mortars with cement as the only binder present a more compact and less porous structure [4]. Moreover, the fibres' addition increased the water absorption capillary coefficient at 28 days, regardless of the type of natural fibres used. Flax fibres presented the highest increase among the fibre-reinforced mortars, as the capillary coefficient had an increment of about $25 \%$ when compared to the REF 1:1:6. This could be due to the fibres high water absorption.

On the other hand, the water absorption capillary coefficient at 365 days of the modified mortars decreased in comparison with the reference cement-lime mortar. $\mathrm{W}$ $1.5-20 \mathrm{cl}$ decreased around $11 \%$ when compared to REF 1:1:6. Thus, it was found that the addition of fibres does not significantly affect the water absorption by capillarity of the mortars over time. 


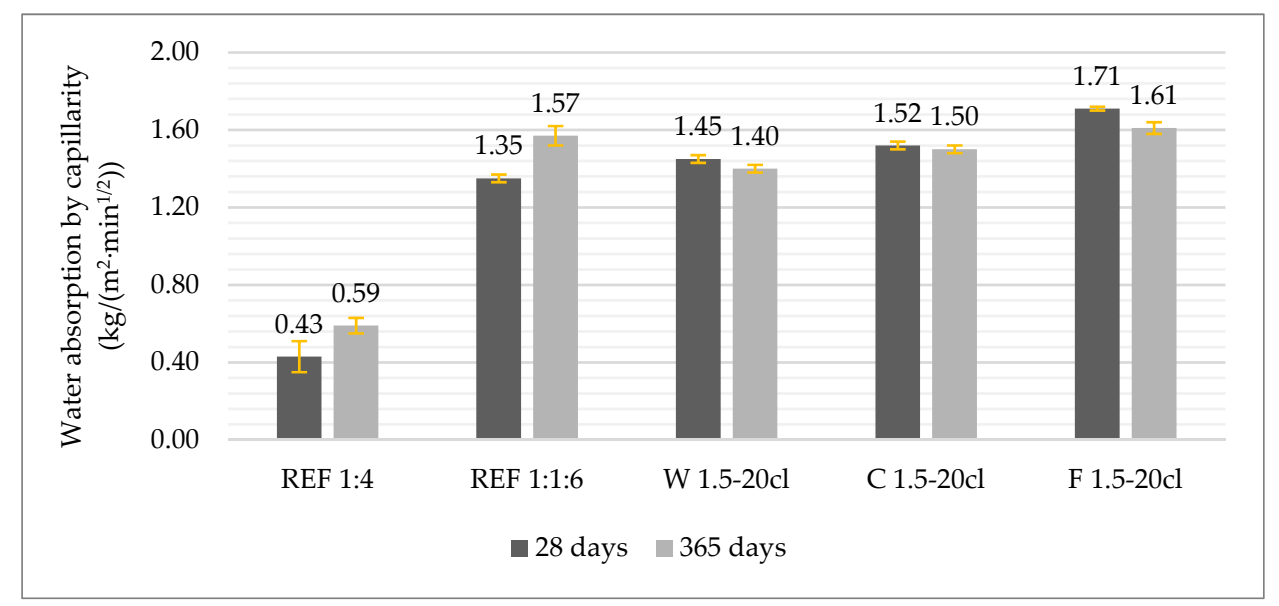

Figure 4. Water absorption by capillarity coefficient.

Figure 5 presents the water absorption curves of the mortars. It shows that, as expected, the mortars with fibres presented a higher water absorption than the reference mortars at 28 days. For mortars produced with cement as the only binder, a lower water absorption is observed; therefore, it can be concluded that the addition of air-lime increases the volume of capillary pores inside the mortars. From the water absorption curves, it was observed that, even though the mortars with fibres presented a higher capillary coefficient, the total amount of water absorbed in the test is similar to that of the reference cement-lime mortar.

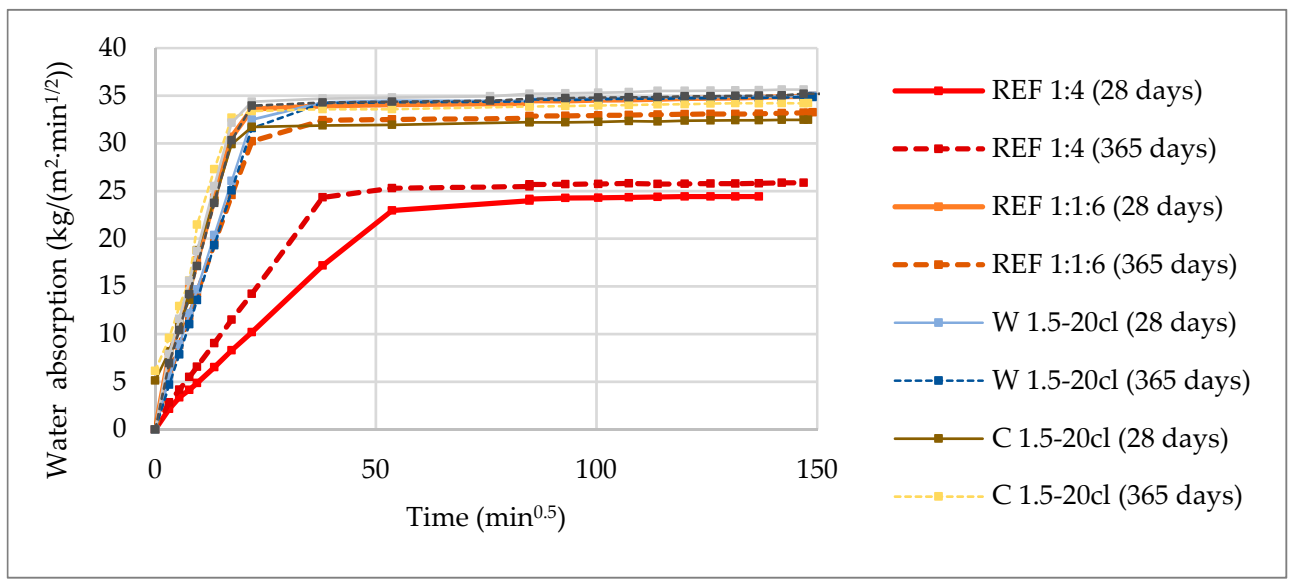

Figure 5. Water absorption by capillarity curves.

It was observed that the capillary coefficient of the fibre-reinforced mortars decreased over time. In fact, with the fibres' addition, the capillary coefficient of the mortars decreased from 28 to 365 days and the maximum absorbed water was also slighted reduced. On the other hand, at 365 days, the reference mortars presented an increase in the capillary coefficient and, in the case of the 1:4 mortar, also an increase of the maximum water absorption, when compared to the results obtained at 28 days. REF 1:4 and REF 1:1:6 increased, at 365 days, the capillary coefficient in about $37 \%$ and $16 \%$, respectively, when compared to the values obtained at 28 days.

Zhao et al. [29] noticed a similar behaviour in mortars with pineapple leaf fibre and ramie fibre. The natural fibre-reinforced composites exhibited a relatively higher water absorption by capillarity at 28 days. This could be mainly due to the water absorption of the fibres used. 


\subsubsection{Water Evaporation upon Drying}

A drying test was performed immediately after the water absorption by capillarity test and the curves for all the mortars under analysis, per square root of time, at 28 and 365 days, are presented in Figure 6.
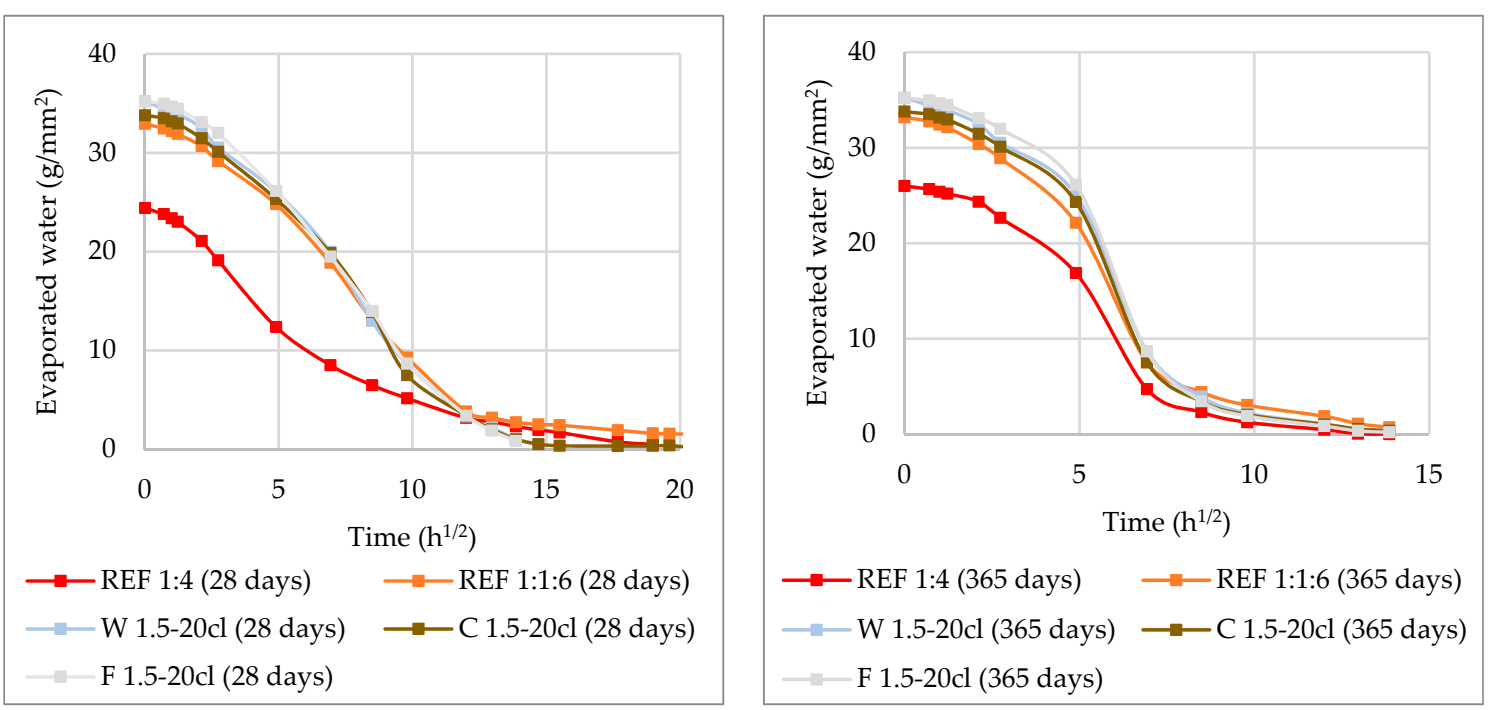

Figure 6. Drying curves of the mortars at 28 and 365 days.

The drying test measures the time of water evaporation of the mortars. It was found that, even though the fibre-reinforced mortars presented higher water absorption capillary coefficient, the water was able to evaporate faster when compared to the reference mortars. This increase in the evaporation rate is mainly due to the larger pores within the modified mortars, which is most likely due to their higher water/binder ratio [16-18]. It can be seen that all the mortars increased the evaporation velocity over time. A fast water evaporation is a positive factor to the render, which should not retain water within its structure.

\subsubsection{Open Porosity}

Open porosity measures the total volume of interconnected pores inside the mortars. The results of this test are presented in Figure 7. At early ages, it was observed that the fibres' addition slightly increased the mortars' porosity. However, over time, it was found that the incorporation of fibres in cement-lime mortars did not affect the open porosity. At 365 days, wool and flax fibres slightly reduced the open porosity of the mortars, whereas coir fibrereinforced mortars increased it by approximately 1.8\% when compared to REF 1:1:6.

It is clear that the mortars with cement as the only binder presented the lowest open porosity values. This is due to the cement matrix, which is characterized by less and smaller pores and higher strength when compared to the lime-based binder matrix [30].

Giosuè et al. [31] also found that the incorporation of wool fibres increased the open porosity of the mortars at early ages. The authors related this increment to the presence of fibres that generate a higher pore diameter inside the mortars, due to their interfacial bond with the matrix. Larger capillary pores would reflect in higher capillary coefficients, which indeed was evidenced at 28 days, thus it can be an explanation as well for the increments in porosity at this study at that age. 


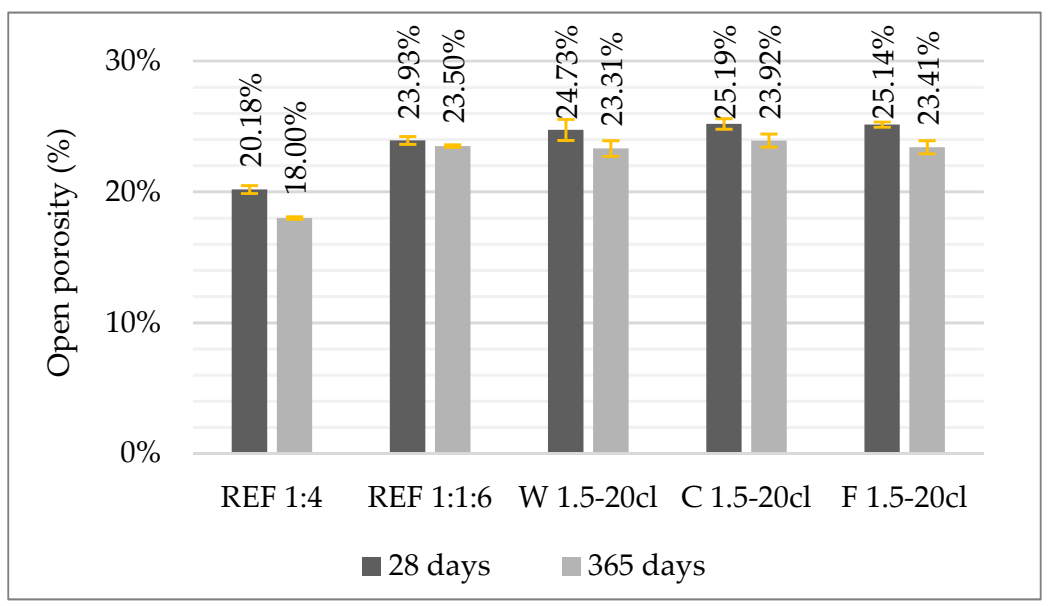

Figure 7. Open porosity of the mortars studied.

\subsubsection{Water Permeability}

The permeability to water under pressure test, which measures the amount of water absorbed under pressure, per unit area, was performed at 28 days and the results are presented in Figure 8. It was observed that the addition of natural fibres slightly reduced the permeability to water under pressure. The cement-lime mortar with flax fibres had the lowest value among the other mortars. As water absorption results pointed out to larger capillary pores for the reinforced mortars at 28 days, a possible explanation for this decrease of permeability under pressure may be the reduction of microcracks, which do not affect the capillary water absorption but reflect on the absorption under pressure. Less microcracks may happen as an effect of the fibres' addition.

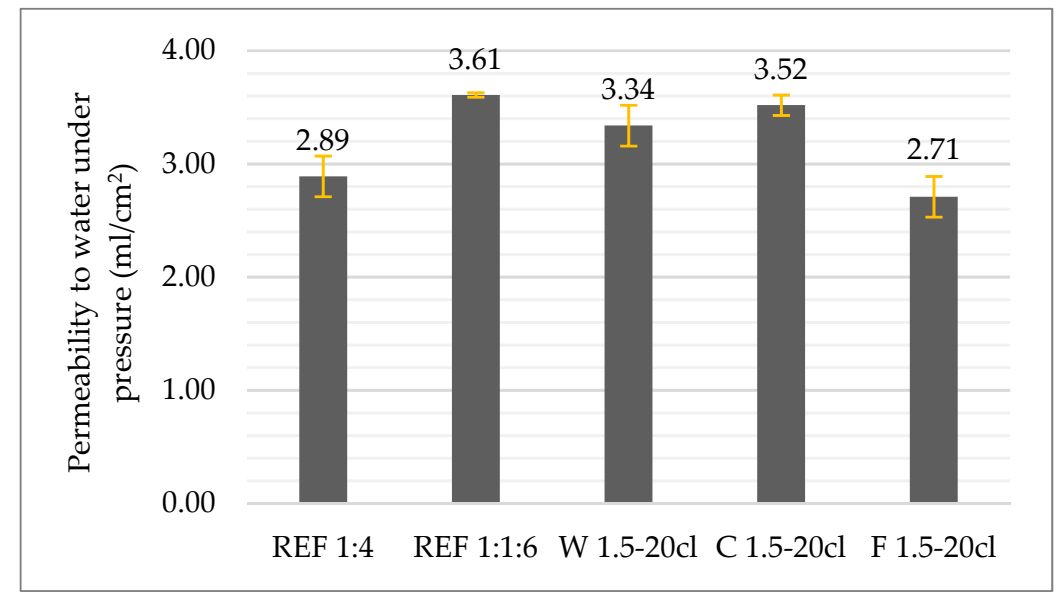

Figure 8. Permeability to water under pressure of the mortars at 28 days.

A decrease in permeability is seen as a positive factor, as it suggests that liquid water has greater difficulty in penetrating the mortar. Even though the fibre-reinforced mortars presented a higher water absorption capillary coefficient, it was found from the results of open porosity and of permeability to water under pressure that the fibres' addition did not negatively affect the mortars' global behaviour towards water protection.

\subsubsection{Modulus of Elasticity}

The ultra-sound pulse velocity measurement indicates the mortars compacity and stiffness and may also reveal the presence of cracks or voids. The test procedure, using the indirect method, involves measuring the wave propagation time from an emitter source to a receptor source. The transmitter is fixed at a specific point and the receptor 
moves at consecutive distances, on the surface of the mortar layer applied on a brick. The transmission time between each two measurement points is determined, as shown in Figure 9. In this method, to calculate the velocity of the ultrasound wave, the values are introduced in a graph, and the slope of the regression line represents the pulse velocity. The dynamic modulus of elasticity was calculated from the determined velocity.

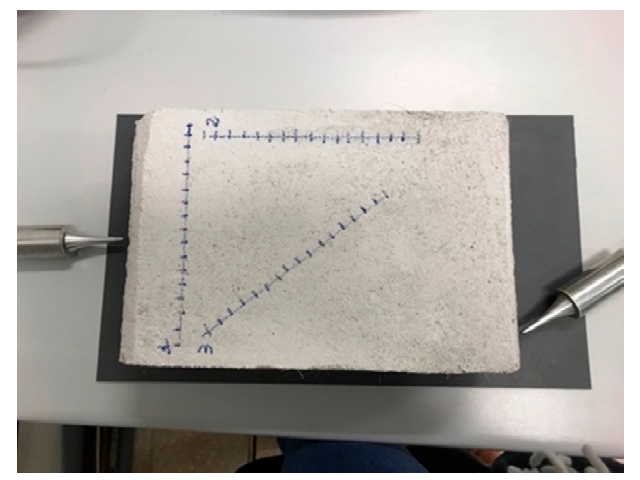

Figure 9. Modulus of elasticity by ultrasound pulse velocity.

The results of modulus of elasticity by ultra-sound pulse velocity test are presented in Figure 10. It was noticed that the modulus of elasticity of the mortars with binary binder is lower than that of the reference cement mortar, at 28 days. This result suggests that the cement mortars are more compact and less porous [4] than the lime-cement ones, as expected. The fibres' addition reduced the modulus of elasticity of the mortars, which indicates that the natural fibre-reinforced mortars are more deformable than the reference ones. This could be due to the lower modulus of elasticity of the fibres, which reduces the global modulus of elasticity of the mortars. Additionally, the incorporation of fibres required more mixing water to achieve the intended workability, which interferes in the porosity and consequently the modulus of elasticity of the mortars.

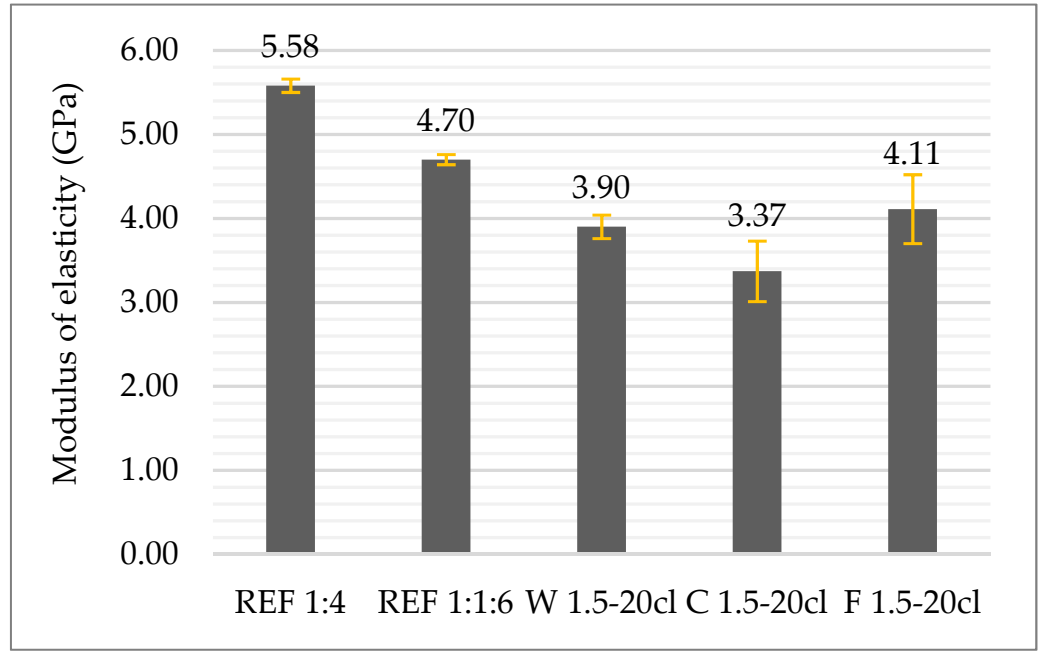

Figure 10. Modulus of elasticity of the mortars at 28 days.

\subsubsection{Dimensional Variation}

The dimensional variation (shrinkage) test measures the dimensional longitudinal changes over time in the mortars. This test was performed up to 90 days and the results are presented in Figure 11. REF 1:4 presented the lowest shrinkage when compared to the mortars with cement and lime as binders. This was to be expected since air-lime has a higher specific surface than cement. Thus, it increased the water film absorbed by the fine particles that enhances the dimensional variation, i.e., the increase of fines led to increased 
shrinkage. As a matter of fact, the carbonation process and removal of the absorbed water from the capillary pores of the cement and lime mortars presented higher dimensional variation [30].

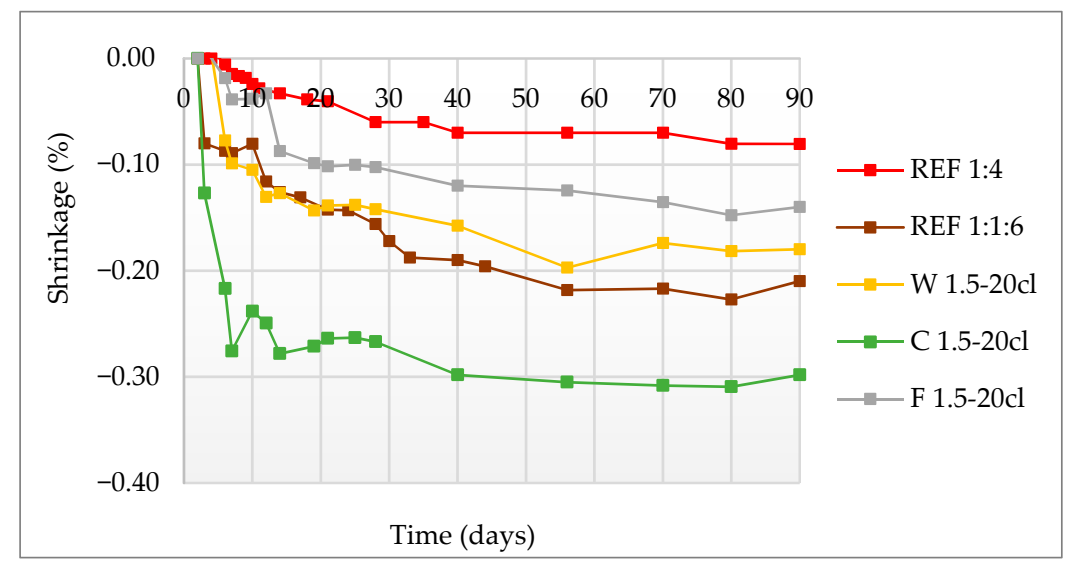

Figure 11. Shrinkage of the mortars.

The largest dimensional variation was for the coir fibre-reinforced mortar. Usually, a high dimensional instability can negatively affect the cracking behaviour of the render, and consequently the durability of the wall. However, the increase in shrinkage presented by the coir fibre-reinforced mortars may not affect the durability of these mortars, since the results of other tests indicate that C 1.5-20cl presented the lowest modulus of elasticity, which indicates more deformability under stress. Flax and wool fibres' mortar presented lower shrinkage than REF 1:1:6. At 90 days, $W$ 1.5-20cl and F 1.5-20cl showed a decrease of up to $15 \%$ and $33 \%$, respectively. These results may lead to less susceptibility to cracking.

\subsubsection{Adherence Strength}

Rendering mortars should have an adequate adhesive strength to the substrate, since a good adhesion contributes to a good distribution of the stresses, which prevents cracking and detachment of the render [32]. The interface between substrate and the render is correlated to several other mortars' properties, such as watertightness, susceptibility to cracking, mechanical strengths. Moreover, an adequate adherence strength may increase the durability of the walls. The adherence strength test results are presented in Figure 12.

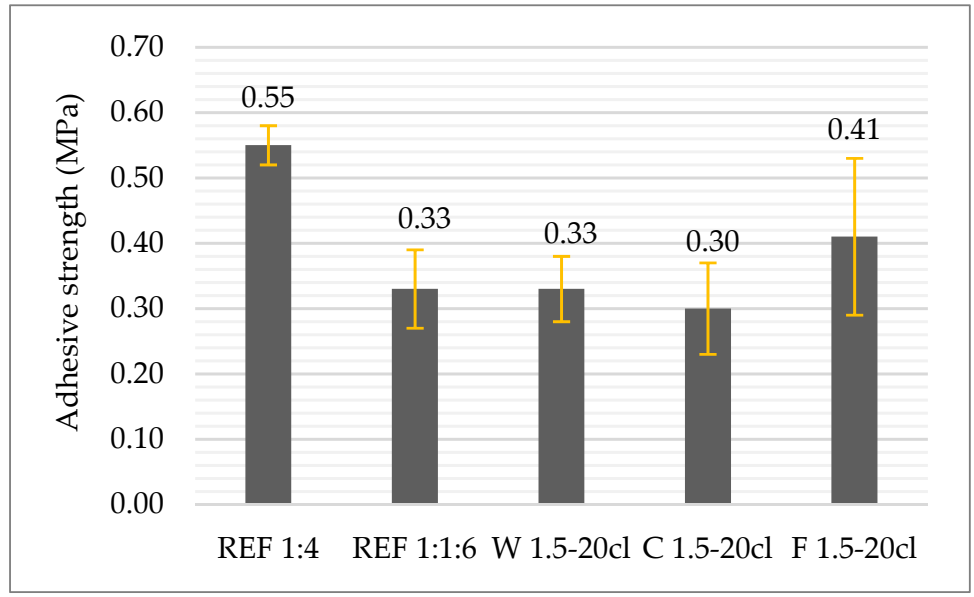

Figure 12. Adherence strength of the mortars at 28 days.

From the results, it can be seen that the reference cement mortar presented the highest adherence strength. Thus, it was concluded that the use of air-lime reduced the adherence 
strength of the mortars. In general, the type of fracture of the mortars analysed was mainly type A, i.e., the fracture occurred at the interface between the mortars and the substrate.

The fibres' addition presented different effects concerning the type of fibres. For flax fibres, the adherence strength of the reinforced mortars was approximately $24 \%$ higher than that of REF 1:1:6, at 28 days. Wool fibre-reinforced mortars obtained similar values to those of the reference cement-lime mortar. On the other hand, mortars with coir fibres slightly reduced the adherence strength of the mortars when compared to the others.

\subsection{Evaluation of Durability Performance of the Mortar Based on the Artificial Accelerated Ageing Test}

The durability of renders is fundamentally related to some anomalies of the mortars, namely cracking, penetration of water by capillarity, loss of adherence, etc. The physical mechanisms of mortars degradation are mainly related with water, in liquid, vapour, and frozen states, through salts dissolution and crystallization, freeze-thaw cycles. Change in volume is another significant physical process involved in the degradation of mortars [3]. The durability of the mortars was evaluated through an artificial accelerated ageing test.

\subsubsection{Visual Aspect}

The visual aspect analysis intended to evaluate the susceptibility to cracking is visible to the naked eye. The mortars were applied on a ceramic brick (20 mm mortar layer), cured for 28 days and submitted to the artificial accelerated ageing test. From Figures 13-17, the specimens before, during and after the accelerated ageing cycles can be seen. The images of the specimens were analysed in order to obtain a visual observation of potential cracks or disaggregation.

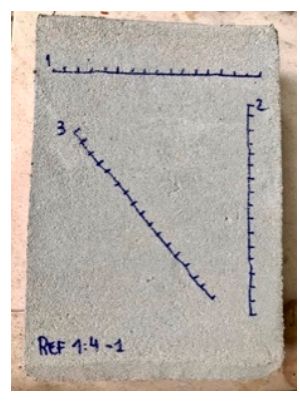

Before ageing

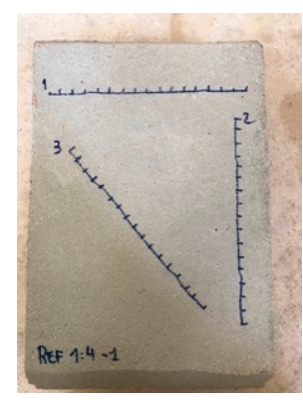

1st heating-freezing cycle

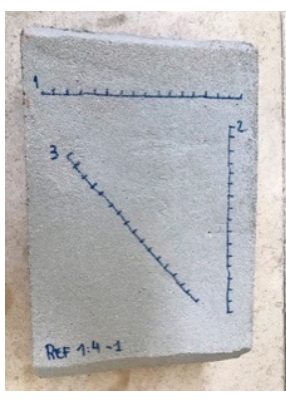

2nd heating-freezing cycle

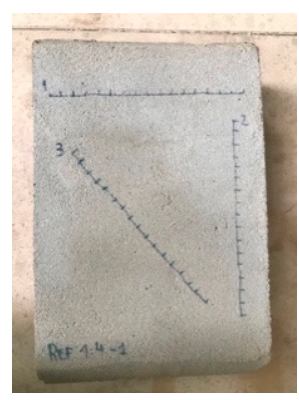

1st humidification-freezing cycle

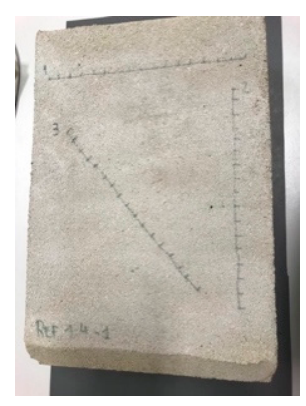

2nd humidification-freezing cycle

Figure 13. Visual aspect of the reference cement mortar during the artificial ageing test.

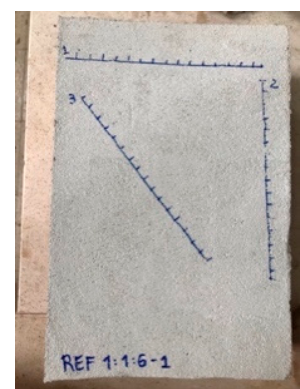

Before ageing

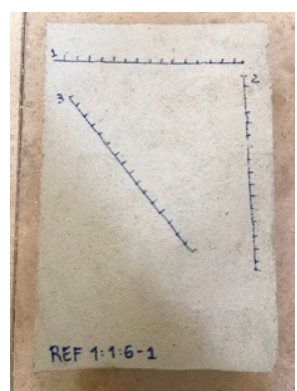

1st heating-freezing cycle

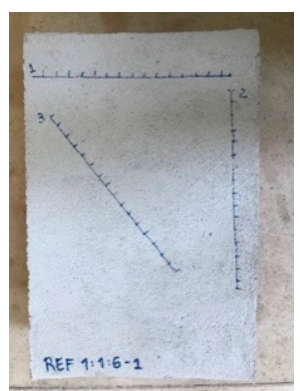

2nd heating-freezing cycle

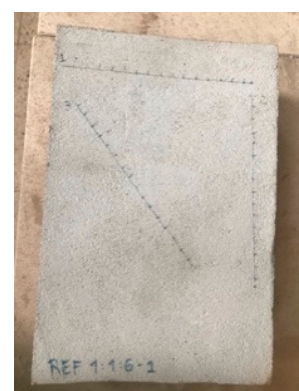

1st humidification-freezing cycle

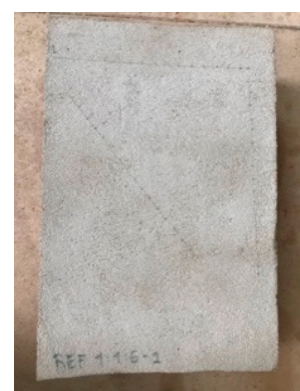

2nd humidification-freezing cycle

Figure 14. Visual aspect of the reference cement-lime mortar during the artificial ageing test. 


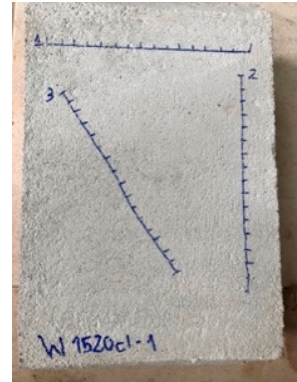

Before ageing

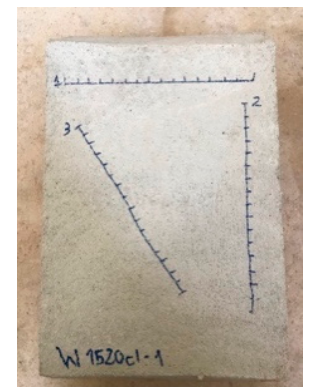

1st heating-freezing cycle

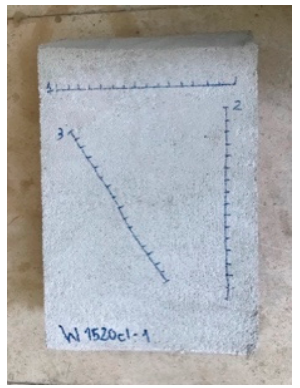

2nd heating-freezing cycle

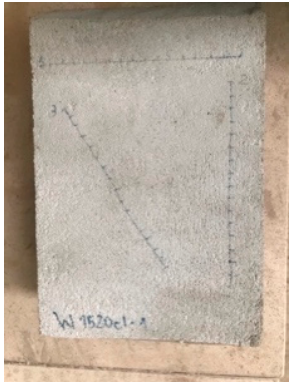

1st humidification-freezing cycle

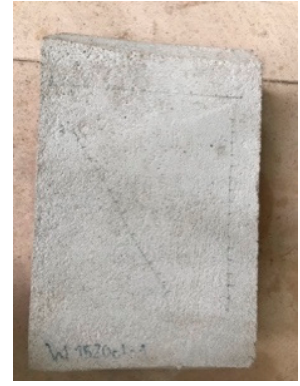

2nd humidification-freezing cycle

Figure 15. Visual aspect of the wool fibre cement-lime mortar during the artificial ageing test.

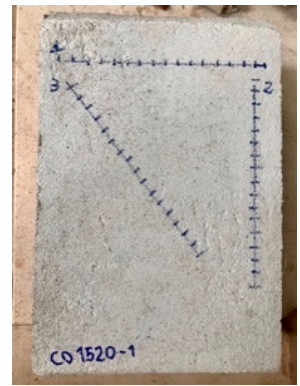

Before ageing

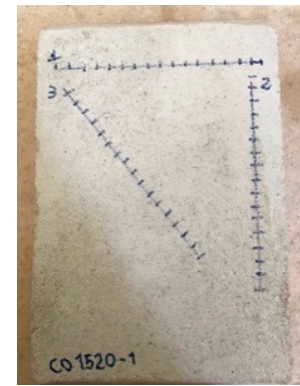

1st heating-freezing cycle

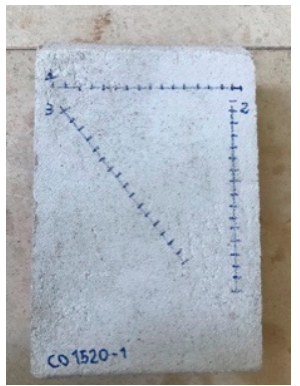

2nd heating-freezing cycle

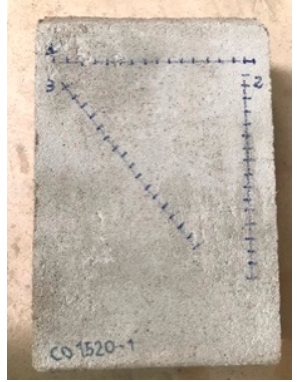

1st humidification-freezing cycle

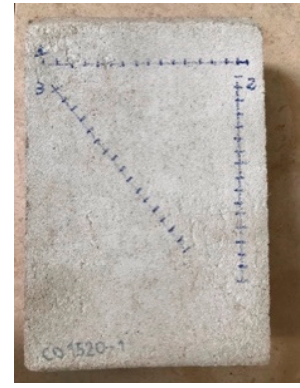

2nd humidification-freezing cycle

Figure 16. Visual aspect of the coir fibre-reinforced cement-lime mortar during the artificial ageing test.

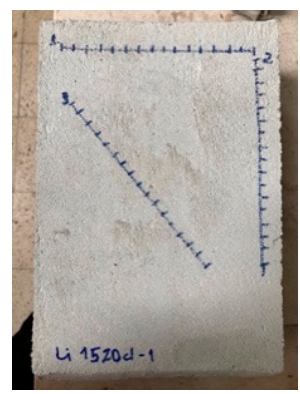

Before ageing

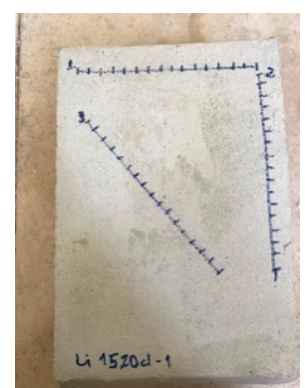

1st heating-freezing cycle

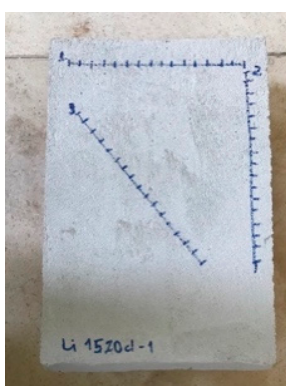

2nd heating-freezing cy-

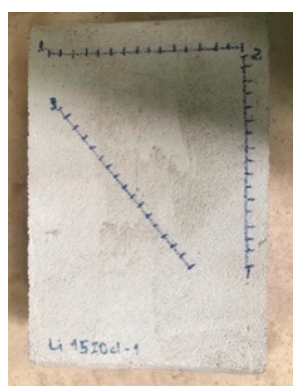

1st humidification-freezing cycle

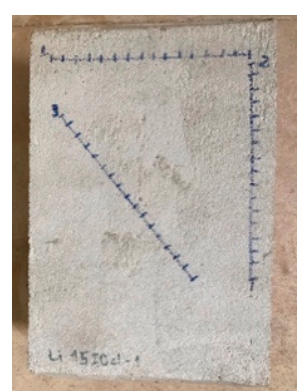

2nd humidification-freezing cycle

Figure 17. Visual aspect of the flax fibre-reinforced cement-lime mortar during the artificial ageing test.

It is clear that a brick's surface is a limited area of application, which does not guarantee that there is no cracking in the application in larger areas. However, this test is merely a first approach of this analysis, to determine what is expected to happen on site.

\subsubsection{Modulus of Elasticity before and after Ageing}

The modulus of elasticity was measured through the ultra-sound pulse velocity test, before and after the ageing process. The results of this test are presented in Table 2. From the results, it was observed that the modulus of elasticity of the mortar with cementlime increased after the artificial ageing. This could be due to an incremented hydration of the cement binder and also an increased carbonation of lime, especially during the humidification-freezing cycles where the abundant water may enhance those reactions, which increase the mechanical characteristics of the mortars and consequently the propagation velocity. 
Table 2. Modulus of elasticity by ultra-sound pulse velocity.

\begin{tabular}{ccccc}
\hline \multirow{2}{*}{ Mortar } & \multicolumn{2}{c}{ Before Ageing (28 Days) } & \multicolumn{2}{c}{ After Ageing } \\
\cline { 2 - 5 } & E (GPa) & $\boldsymbol{\sigma}$ & E (GPa) & $\sigma$ \\
\hline REF 1:4 & 5.58 & 0.08 & 5.32 & 0.24 \\
\hline REF 1:1:6 & 4.70 & 0.06 & 4.75 & 0.63 \\
\hline W 1.5-20cl & 3.90 & 0.14 & 4.27 & 0.64 \\
\hline C 1.5-20cl & 3.37 & 0.36 & 4.09 & 0.30 \\
\hline F 1.5-20cl & 4.11 & 0.41 & 4.74 & 0.27 \\
\hline
\end{tabular}

On the other hand, for the reference cement mortar, the modulus of elasticity decreased after ageing. This phenomenon can be attributed to microcracks that may occur due to thermal variations, which decrease the propagation velocity. Therefore, mortars with cement as the only binder may prevail the microcracking over the cement hydration effect, after the ageing test.

\subsubsection{Water Permeability before and after Ageing}

The permeability to water under pressure test was performed before and after ageing, and the results are presented in Table 3. There, when the values were compared before and after the artificial accelerated ageing test, a decrease in permeability to water under pressure was noticed for the reference cement mortar, and an increase for the mortars with cement-lime. This is mainly due to the cement hydration, which makes the mortars with cement as the only binder more compact and harder to be penetrated by the water. On the other hand, mortars with cement and lime as binders are more permeable to water under pressure after ageing test.

Table 3. Permeability to water under pressure results.

\begin{tabular}{ccccc}
\hline \multirow{2}{*}{ Mortar } & \multicolumn{2}{c}{ Before Ageing (28 Days) } & \multicolumn{2}{c}{ After Ageing } \\
\cline { 2 - 5 } & $\begin{array}{c}\text { Permeability to Water under } \\
\text { Pressure }\left(\mathbf{m L} / \mathbf{c m}^{2}\right)\end{array}$ & $\sigma$ & $\begin{array}{c}\text { Permeability to Water under } \\
\text { Pressure }\left(\mathbf{m L} / \mathbf{c m}^{2}\right)\end{array}$ & 0.18 \\
\hline REF 1:4 & 2.89 & 0.02 & 2.26 & 0.52 \\
\hline REF 1:1:6 & 3.61 & 0.18 & 3.70 & 0.01 \\
\hline W 1.5-20cl & 3.34 & 0.09 & 4.24 & 0.54 \\
\hline C 1.5-20cl & 3.52 & 0.18 & 3.43 & 0.00 \\
\hline F 1.5-20cl & 2.71 & & 0.24 \\
\hline
\end{tabular}

The permeability to water under pressure at 28 days results indicate that the mortars with incorporation of natural fibres were less permeable than REF 1:1:6. Moreover, it was noticed that, after the accelerated ageing test, the natural fibre-reinforced mortars also presented in general lower values of permeability under pressure when compared to the reference cement-lime mortar. These decreases are attributable to the contribution of the fibres' addition to prevent the mortars' cracking.

\subsubsection{Open Porosity before and after Ageing}

The open porosity of the mortars applied on a brick was performed before and after ageing, and the results are presented in Table 4 . Before ageing, the mortar with only cement as the binder showed the lowest open porosity. This was expected since cement mortars are more compact than mortars with cement and lime as binary binder. It was also evidenced that the addition of fibres increased the open porosity of mortars at 28 days. After the accelerated ageing test, an increase in the open porosity results of the two reference mortars was found. However, the reference mortar with cement presented the highest value of 
porosity among the mortars. This could be attributed to the occurrence of microcracks since these mortars present higher stiffness.

Table 4. Open porosity of the mortars applied on a brick.

\begin{tabular}{ccccc}
\hline \multirow{2}{*}{ Mortar } & \multicolumn{2}{c}{ Before Ageing (28 Days) } & \multicolumn{2}{c}{ After Ageing } \\
\cline { 2 - 5 } & Open Porosity (\%) & $\boldsymbol{\sigma}$ & Open Porosity (\%) & $\boldsymbol{\sigma}$ \\
\hline REF 1:4 & 16.50 & 0.54 & 18.83 & 0.22 \\
\hline REF 1:1:6 & 17.22 & 0.34 & 17.68 & 0.57 \\
\hline W 1.5-20cl & 18.10 & 0.20 & 18.65 & 0.73 \\
\hline C 1.5-20cl & 18.05 & 0.26 & 18.02 & 0.98 \\
\hline F 1.5-20cl & 18.25 & 0.30 & 18.20 & 0.77 \\
\hline
\end{tabular}

It was observed that the fibre-reinforced mortars suffered a slight increase of porosity in the case of the wool fibre and showed no variation of porosity in the other two cases, most likely due to the effect of the fibres in hindering microcracking. These results confirm the influence of the fibres in reducing the cracking susceptibility.

\subsubsection{Adherence to Substrate before and after Ageing}

The results of the adherence strengths of the mortars are presented in Table 5, before and after ageing. A predominance of type A and B failures was found, defined by EN 1015-12 [33], respectively, as failure at the interface between the mortar and the substrate and failure in the mortar itself. The mortars with cement-lime as a binary binder presented a lower adherence to the substrate than the cement mortar. This is because the bond between the coating and the substrate is more effective for cement as binder.

Table 5. Adherence resistance results.

\begin{tabular}{ccccccc}
\hline Mortar & \multicolumn{3}{c}{ Before Ageing (28 Days) } & \multicolumn{3}{c}{ After Ageing } \\
\cline { 2 - 7 } & $\begin{array}{c}\text { Adherence } \\
\text { (MPa) }\end{array}$ & $\begin{array}{c}\text { Predominant } \\
\text { Type of Failure }\end{array}$ & $\sigma$ & $\begin{array}{c}\text { Adherence } \\
\text { (MPa) }\end{array}$ & $\begin{array}{c}\text { Predominant } \\
\text { Type of Failure }\end{array}$ & $\sigma$ \\
\hline REF 1:4 & 0.55 & $\mathrm{~A}$ & 0.03 & 0.76 & $\mathrm{~A}$ & 0.03 \\
\hline REF 1:1:6 & 0.33 & $\mathrm{~A}$ & 0.06 & 0.41 & $\mathrm{~A} / \mathrm{B}$ & 0.33 \\
\hline W 1.5-20cl & 0.33 & $\mathrm{~A}$ & 0.05 & 0.38 & $\mathrm{~A}$ & 0.46 \\
\hline C 1.5-20cl & 0.30 & $\mathrm{~A} / \mathrm{B}$ & 0.07 & 0.34 & $\mathrm{~A}$ & 0.40 \\
\hline F 1.5-20cl & 0.41 & $\mathrm{~A}$ & 0.12 & 0.43 & $\mathrm{~B}$ & 0.36 \\
\hline
\end{tabular}

It was noticed that all the mortars increased the adhesive strength after the artificial accelerated ageing test. This is attributable to the delayed binder hydration and carbonation during the humidity and freeze cycle effect. Those reactions imply a decrease of the voids inside the mortars, which increase the mortars' compactness and mechanical strength.

Figure 18 presents the specimens after the adherence strength test of the mortars after artificial accelerated ageing process. 


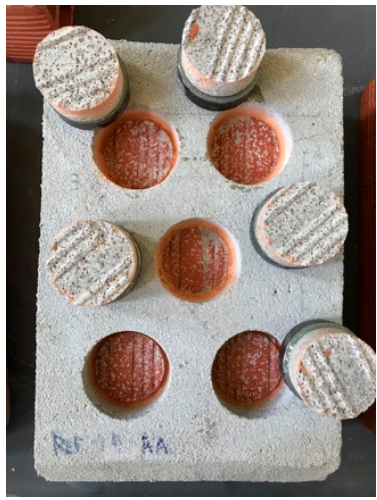

(a)

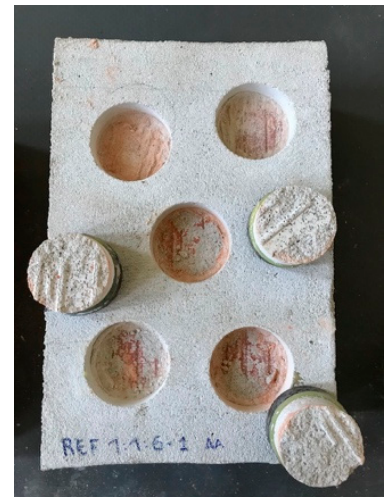

(b)

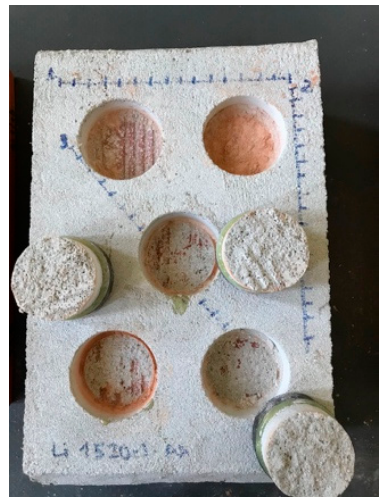

(c)

Figure 18. Adherence strength test after artificial accelerated ageing: (a) REF 1:4 (type A), (b) REF 1:1:6 (type A/B) and (c) F 1.5-20cl (type B).

\section{Conclusions}

From the results obtained, a better characterization of binary mortars with natural fibres was performed. The main conclusions that can be drawn are the following:

- The fibres' addition increased the water absorption capillary coefficient of the mortars. However, the total amount of water absorbed was similar for all the mortars with cement and lime as binary binder. Additionally, the drying rate increases in the mortars with fibres, which reduces the risk of long time wetting;

- Regarding the open porosity of the mortars, it was concluded that, at 365 days, the incorporation of fibres did not affect the volume of interconnected voids inside the mortars. Furthermore, after the artificial accelerated ageing test, the mortars with natural fibres were less permeable to water under pressure, which indicates less microcracks inside their structure;

- In terms of the cracking performance, it was confirmed that the addition of fibres reduced the modulus of elasticity of the mortars, which indicates that the natural fibre-reinforced mortars were able to absorb more imposed deformations than those without fibres. This effect could be due to the lower modulus of elasticity of the fibres when compared to that of the reference mortars;

- A decrease in shrinkage was observed in the mortars with flax and wool fibres when compared with the reference mortar, which suggest that these mortars are less susceptible to cracking when compared to REF 1:1:6;

- At 28 days, the incorporation of fibres in cement-lime mortars did not show a significant effect on the adherence strength. Nonetheless, after the artificial accelerated ageing process, the type of natural fibres affected differently in the mortars. The incorporation of flax fibres increased $5 \%$ the adhesive strength when compared to that of REF 1:1:6. On the other hand, when coir fibres were added, a reduction of about $17 \%$ was observed;

- Concerning the durability of the mortars, it was found that the addition of natural fibres hindered the microcracking of the lime-cement mortars during the accelerated ageing cycles, as shown by the higher results of the dynamic modulus of elasticity of the reinforced mortars after ageing compared to before ageing. Additionally, although all lime-cement mortars suffered an increase of the water permeability under pressure after ageing, which increase was slight compared to the more pronounced increment registered by the reference lime-cement mortar. The permeability results are somehow confirmed by the porosity values, which indicate that the reinforced mortars suffer no increase or, in one case, only a slight increase of porosity during the ageing cycles. These results suggest an improvement of durability of the mortars with incorporation of natural fibres and do not indicate an effect of degradation of the fibres. 
Overall, it can be concluded that the incorporation of natural fibres in rendering mortars can increase the protection of the wall against external actions by reducing the susceptibility to cracking and the permeability to water under pressure after ageing. They also enhance the durability of the mortars by prolonging the time of the protection ability, as shown by the results after artificial ageing cycles. Besides the fibres' benefits, it was found that the use of air-lime in substitution of the part of cement increased the mortars' deformability when compared to the mortars with only cement as binder. Therefore, the incorporation of natural waste fibres in cement-lime rendering mortars may increase the mortars' resistance to weathering and, consequently, increase the durability of the walls.

Author Contributions: C.M.P. performed the experiments in the Building Finishes and Thermal Insulation Unit (NRI) of the National Laboratory for Civil Engineering of Portugal (LNEC). The analyses of the tests and the interpretation of the results were developed by C.M.P., R.V. and J.d.B. The original draft of this paper was written by C.M.P. and the review and editing were performed by R.V. and J.d.B. All authors have read and agreed to the published version of the manuscript.

Funding: This research was funded by Portuguese Foundation for Science and Technology (FCT) (PD/BD/135193/2017).

Institutional Review Board Statement: Not applicable.

Informed Consent Statement: Not applicable.

Data Availability Statement: The data presented in this study are available on request from the corresponding author.

Acknowledgments: The authors would like to acknowledge the REuSE project from National Laboratory for Civil Engineering of Portugal (LNEC), the research unit CERIS from Instituto Superior Técnico (IST), and the Portuguese Foundation for Science and Technology for the support given to this research.

Conflicts of Interest: The authors declare no conflict of interest.

\section{References}

1. EN 998-1. Specification for Mortar for Masonry_Part 1: Rendering and Plastering Mortar; European Committee for Standardization (CEN): Brussels, Belgium, 2010.

2. Lanas, J.; Sirera, R.; Alvarez, J. Study of the mechanical behavior of masonry repair lime-based mortars cured and exposed under different conditions. Cem. Concr. Res. 2006, 36, 961-970. [CrossRef]

3. Arizzi, A.; Viles, H.; Cultrone, G. Experimental testing of the durability of lime-based mortars used for rendering historic buildings. Constr. Build. Mater. 2012, 28, 807-818. [CrossRef]

4. Mosquera, M.J.; Silva, B.; Prieto, B.; Ruiz-Herrera, E. Addition of cement to lime-based mortars: Effect on pore structure and vapor transport. Cem. Concr. Res. 2006, 36, 1635-1642. [CrossRef]

5. Grilo, J.; Faria, P.; Veiga, R.; Silva, A.S.; Silva, V.; Velosa, A. New natural hydraulic lime mortars-Physical and microstructural properties in different curing conditions. Constr. Build. Mater. 2014, 54, 378-384. [CrossRef]

6. Bentur, A.; Kovler, K. Evaluation of early age cracking characteristics in cementitious systems. Mater. Struct./Mater. Et Constr. 2003, 36, 183-190. [CrossRef]

7. Filho, R.D.T.; Scrivener, K.; England, G.L.; Ghavami, K. Durability of alkali-sensitive sisal and coconut fibres in cement mortar composites. Cem. Concr. Compos. 2000, 22, 127-143. [CrossRef]

8. Joshi, S.V.; Drzal, L.T.; Mohanty, A.K.; Arora, S. Are natural fiber composites environmentally superior to glass fiber reinforced composites? Compos. Part A Appl. Sci. Manuf. 2004, 35, 371-376. [CrossRef]

9. Pederneiras, C.M.; Veiga, R.; de Brito, J. Effects of the Incorporation of Waste Fibres on the Cracking Resistance of Mortars: A Review. Int. J. Green Technol. 2018, 4, 38-46.

10. Wei, J.; Meyer, C. Utilization of rice husk ash in green natural fiber-reinforced cement composites: Mitigating degradation of sisal fiber. Cem. Concr. Res. 2016, 81, 94-111. [CrossRef]

11. Silva, F.D.; Mobasher, B.; Filho, R.D.T. Cracking mechanisms in durable sisal fiber reinforced cement composites. Cem. Concr. Compos. 2009, 31, 721-730. [CrossRef]

12. Ramakrishna, G.; Sundararajan, T. Studies on the durability of natural fibres and the effect of corroded fibres on the strength of mortar. Cem. Concr. Compos. 2005, 27, 575-582. [CrossRef]

13. Santos, S.F.; Schmidt, R.; Almeida, A.E.F.S.; Tonoli, G.H.D.; Savastano, H. Supercritical carbonation treatment on extruded fibre-cement reinforced with vegetable fibres. Cem. Concr. Compos. 2015, 56, 84-94. [CrossRef]

14. Jóźwiak-Niedźwiedzka, D.; Fantilli, A.P. Wool-reinforced cement based composites. Materials 2020, 13, 3590. [CrossRef] [PubMed] 
15. Ardanuy, M.; Claramunt, J.; Filho, R.D.T. Cellulosic fiber reinforced cement-based composites: A review of recent research. Constr. Build. Mater. 2015, 79, 115-128. [CrossRef]

16. Pederneiras, C.M.; Veiga, R.; de Brito, J. Physical and Mechanical Performance of Coir Fiber-Reinforced Rendering Mortars. Materials 2021, 14, 1-15.

17. Pederneiras, C.M.; Veiga, R.; de Brito, J. Rendering mortars reinforced with natural sheep's wool fibers. Materials 2019, 12, 3648. [CrossRef]

18. Pederneiras, C.M.; Veiga, R.; de Brito, J. Rendering mortars reinforced with flax fibres for building rehabilitation: Influence of fibres on susceptibility to cracking (In Portuguese). In ENCORE 2020: $4^{\circ}$ Encontro de Conservação e Reabilitação de Edifícios; Lisbon, 1st ed.; Laboratório Nacional de Engenharia Civil: Lisboa, Portugal, 2020; pp. 1-10, ISBN 978-972-49-2313-0. [CrossRef]

19. EN 197-1. Cement Part 1: Composition, Specifications and Conformity Criteria for Common Cements; European Committee for Standardization (CEN): Brussels, Belgium, 2011.

20. EN 459-1. Building Lime; Part 1: Definitions, Specifications and Conformity Criteria; European Committee for Standardization (CEN): Brussels, Belgium, 2015.

21. EN 1015-18. Methods of Test for Mortar for Masonry_Part 18: Determination of Water Absorption Coefficient Due to Capillary Action of Hardened Mortar; European Committee for Standardization (CEN): Brussels, Belgium, 2002.

22. EN 16322. Conservation of Cultural Heritage-Tests Methods_-Determination of Drying Properties; European Committee for Standardization (CEN): Brussels, Belgium, 2013.

23. EN 1936. Natural Stone Test Methods. Determination of Real Density and Apparent Density and Total and Partial Open Porosity; European Committee for Standardization (CEN): Brussels, Belgium, 2007.

24. EN 1015-21. Methods of Test for Mortar for Masonry_Part 21: Determination of the Compatibility of One-Coat Rendering Mortars with Substrates; European Committee for Standardization (CEN): Brussels, Belgium, 2002.

25. EN 12504-4. Testing Concrete in Structures. Part 4: Determination of Ultrasonic Pulse Velocity; European Committee for Standardization (CEN): Brussels, Belgium, 2007.

26. Cahier 2669-4. Certification CSTB des Enduits Monocouches D'imperméabilisation, Modalités d'essais; Centre Scientifique et Technique du Bâtiment: Marne-la-Vallée, France, 1993.

27. EN 1015-11. Methods of Test for Mortar for Masonry_Part 11: Determination of Flexural and Compressive Strength of Hardened Mortar; European Committee for Standardization (CEN): Brussels, Belgium, 1999.

28. Veiga, M.R.; Velosa, A.L.; Magalhães, A.C. Evaluation of mechanical compatibility of renders to apply on old walls based on a restrained shrinkage test. Mater. Struct./Mater. Et Constr. 2007, 40, 1115-1126. [CrossRef]

29. Zhao, K.; Xue, S.; Zhang, P.; Tian, Y.; Li, P. Application of natural plant fibers in cement-based composites and the influence on mechanical properties and mass transport. Materials 2019, 12, 3498. [CrossRef]

30. Stefanidou, M.; Papayianni, I. The role of aggregates on the structure and properties of lime mortars. Cem. Concr. Compos. 2005, 27, 914-919. [CrossRef]

31. Giosuè, C.; Mobili, A.; Yu, Q.L.; Brouwers, H.J.H.; Ruello, M.L.; Tittarelli, F. Properties of multifunctional lightweight mortars containing zeolite and natural fibers. J. Sustain. Cem. Based Mater. 2019, 8, 214-227. [CrossRef]

32. Santos, A.R.L.d.; Veiga, M.d.R.d.; Silva, A.M.d.S.; de Brito, J.M.C.L. Tensile bond strength of lime-based mortars: The role of the microstructure on their performance assessed by a new non-standard test method. J. Build. Eng. 2020, 29, 101136. [CrossRef]

33. En 1015-12. Methods of Test for Mortar for Masonry_Part 12: Determination of Adhesive Strength of Hardened Rendering and Plastering Mortars on Substrates; European Committee for Standardization (CEN): Brussels, Belgium, 2000. 